\title{
Effectiveness of prenatal teaching on prevention of breast engorgement
}

\author{
Padmasree S. R., Linda Varghese*, Aswathy S. Krishnan
}

Department of Obstetrics and Gynecology Nursing, Amrita College of Nursing, Amrita University, Kochi, Kerala, India

Received: 24 June 2017

Revised: 25 July 2017

Accepted: 29 July 2017

\section{*Correspondence:}

Dr. Linda Varghese,

E-mail: lindasojan@gmail.com

Copyright: (c) the author(s), publisher and licensee Medip Academy. This is an open-access article distributed under the terms of the Creative Commons Attribution Non-Commercial License, which permits unrestricted non-commercial use, distribution, and reproduction in any medium, provided the original work is properly cited.

\section{ABSTRACT}

Background: Breast engorgement is a major issue in the early postpartum period under the influence of hormonal shift and increase milk production. The purpose of this study was to evaluate the prevention, recognition and management of breast engorgement.

Methods: Quasi Experimental, quantitative study conducted in AIMS, Kochi among sixty mothers by Convenience sampling technique. The design used was pre-test post-test control group design. A semi structured knowledge questionnaire, Bristol Breastfeeding Assessment Tool and an Observational checklist were used to collect the data. Prenatal teaching provided to the Experimental group.

Results: The mean pre-test knowledge level of control group was 9.83 and the post-test knowledge was 10.03 . In the Experimental group, the mean pre-test level was 10.20 and the post-test level is 20.76 . The ' $t$ ' value of control group was 0.71 and that of Experimental group was 12.83 which was highly significant at 0.001 level. There was a significant increase in knowledge score in Experimental group. Comparing the breastfeeding practices regarding positioning and attachment in both groups, showed a significant difference at the level of 0.001 but other two aspects, sucking and swallowing were not significant. Comparing the incidence, $13.3 \%$ mothers reported in experimental group whereas $63.3 \%$ in the control group, which showed a remarkable decrease in the incidence of breast engorgement in the former group.

Conclusions: The prenatal teaching was effective in improving the health of mothers as well as practices of breastfeeding and it helped in reduction of the incidence of breast engorgement.

Keywords: Breast engorgement, Mothers, Prenatal teaching

\section{INTRODUCTION}

Breastfeeding is an art. Human milk has no substitute and breast is nature's apparatus for feeding babies. Early initiation of breast feeding helps to develop a bond between the mother and baby. Many a times, feeding becomes troublesome due to various factors. One among that is, engorgement of the breast. Anatomically, the breasts or mammary glands are a milk producing gland which is composed of largely of fat. It is a complex network of branching ducts and sac-like structures lobules, which produce milk. ${ }^{1}$ Breast tissue fluid drains through the lymphatics into the lymph nodes located in the axilla and behind the sternum. Infrequent feeding or ineffective emptying of the breasts, results in congestion and distension of the collecting ductal system and obstruction of lymphatic drainage causing breast engorgement. ${ }^{3}$ According to Academy of Breastfeeding Medicine Protocol Committee, breast engorgement is defined as "the swelling and distension of the breasts," 
usually in the early days of initiation of lactation, caused by vascular dilation as well as the arrival of the early milk. ${ }^{2}$ Statistics indicate the incidence rate of breast engorgement all over the world is 1:8000 and in India it is 1:6500. Engorgement symptoms occur most commonly between days three and five, with more than two-third of women with tenderness on day five, but some as late as day 9-10. ${ }^{3}$ Two-third of women experience at least moderate symptoms. More time spent for breastfeeding in the first 48hours is associated with less engorgement. The twenty percent of postnatal mothers especially primigravida mothers are affected with breast engorgement from 0-4days of postnatal period. ${ }^{4}$

Breast engorgement is one of the common breast implication occur in third and fourth postpartum day due to excessive production of milk, obstruction to outflow of milk or poor removal of milk by the baby. ${ }^{6}$ Engorgement symptoms occur most commonly between days 3 and 5 , in that 2-3 of them experience tenderness on day 5, however some cases late as day 9-10. Breast engorgement is a major issue in the early postpartum period as the breast, under the influence of hormonal shift, increase milk production rapidly. For most women engorgement is at its height from 3 to 5 days after birth and slowly recedes but may last for 2 weeks. ${ }^{7}$

Most of the studies found that the postnatal mothers have only less knowledge about breastfeeding practices. A study done to assess the knowledge, attitude and practice of breastfeeding among postnatal mothers revealed that the knowledge of the mothers was inadequate in areas of time of initiation of breastfeeding (92\%), colostrums feeding $(56 \%)$, duration of exclusive breastfeeding $(38 \%)$, knowledge on expressed breast milk (51\%) and continuation of breastfeeding while baby is sick. Higher maternal age, mothers having better education and belonged to higher socio-economic status and those who received antenatal care from teritiary care centres and private practitioner, showed better scoring when correlated with mothers who were young, less educated and those from lower socio-economic class and those who received primary care. So, there is a need to assess breastfeeding practices. ${ }^{5}$

Statement of the problem: Effectiveness of prenatal teaching on prevention of breast engorgement among mothers admitted in tertiary hospital, Kochi. Objectives of the study was to compare the level of knowledge regarding prevention of breast engorgement among Experimental and Control group. Compare the practices of breastfeeding between the experimental and control group. Compare the incidence of breast engorgement among mothers in Experimental and Control group.

\section{METHODS}

The present study, was intended to assess the effectiveness of prenatal teaching on prevention of breast engorgement among mothers. A quasi experimental research design was used for this study among 60 mothers 8 in Gynaecology wards and OPD in a tertiary hospital, Kochi by using non-probability convenience sampling techniques. The research design adopted for study is Pre-test-Post test control group design. It was to evaluate the effectiveness of prenatal teaching on prevention of breast engorgement. A proforma to collect the background information of mothers, and a semi structured knowledge questionnaire to assess the knowledge regarding prevention of the breast engorgement. The incidence of breast engorgement was assessed using observational checklist and those who reported pain are assessed again by using numerical pain scale. For assessing the breastfeeding practice, a standardized tool by Dr. Jenny Ingram, Bristol Breastfeeding Assessment tool was used. The content of the tool was validated by the subject experts. Data was collected from 12-1-16 to 16-4-16. Analysis was done by using SPSS version 21. Prenatal teaching was given for only Experimental group after pre-test in the antenatal period and the post-test knowledge were assessed in the postnatal period (third day) regarding the knowledge of breast engorgement as well as practices of breastfeeding by administering BBAT. The incidence of breast engorgement also assessed by using Observational Checklist and Numerical Pain scale during postnatal period.

\section{RESULTS}

The present study was intended to evaluate the effectiveness of prenatal teaching on prevention of breast engorgement among mothers. The data collected from 60 mothers who attended the Obstetrics and Gynaecological Department of Amrita Institute of Medical Sciences, Kochi. There was a significant increase in knowledge score regarding prevention of breast engorgement in Experimental group while comparing with that of control group. Comparing the four aspects of breastfeeding practices in BBAT between experimental and control group, chi-square test revealed that positioning and attachment $\left(\chi^{2}=14.958\right)$ shows significant difference at the level of 0.001 but other two aspects, sucking and swallowing $\left(\chi^{2}=7.450\right)$ are not significant and the $p$ value is 0.024 . Comparing the incidence of breast engorgement, $13.3 \%$ mothers only reported breast engorgement in experimental group whereas $63.3 \%$ in the Control group, which shows remarkable decrease in the incidence of breast engorgement in the former group. The majority of subjects in both groups belong to 21-25years, had higher secondary education, housewife and primigravida. Gestational age of the mothers was 3839 weeks and mode of delivery was LSCS. Seven mothers reported breast problems in early pregnancy such as inverted nipples and five mothers reported flat nipples. Majority of the mothers got information from their parents as well as not done the breast examination. Most of the mothers $(66.6 \%)$ in Control group had not adequate milk production whereas $56 \%$ in Experimental group had adequate milk production. 
Table 1: Distribution of mothers based on demographic data $n=60$.

\begin{tabular}{|c|c|c|c|c|}
\hline \multirow{2}{*}{ Demographic data } & \multicolumn{2}{|c|}{ Control $(n=30)$} & \multicolumn{2}{|c|}{ Experimental (n=30) } \\
\hline & Frequency & $\%$ & Frequency & $\%$ \\
\hline \multicolumn{5}{|l|}{ Age (in years) } \\
\hline Below 20 years & 2 & 6.7 & 1 & 3.3 \\
\hline $21-25$ years & 12 & 40 & 15 & 50 \\
\hline $26-30$ years & 6 & 20 & 9 & 30 \\
\hline $31-35$ years & 8 & 26.6 & 3 & 10 \\
\hline $36-40$ years & 2 & 6.7 & 2 & 6.7 \\
\hline Marital Status & 30 & 100 & 30 & 100 \\
\hline \multicolumn{5}{|l|}{ Education } \\
\hline High School & 7 & 23.3 & 5 & 16.7 \\
\hline Higher Secondary & 18 & 60 & 19 & 63.3 \\
\hline Graduate/Postgraduate & 5 & 16.7 & 6 & 20 \\
\hline \multicolumn{5}{|l|}{ Occupation } \\
\hline Govt/Private & 1 & 3.3 & 0 & 0 \\
\hline Business & 14 & 46.7 & 14 & 46.7 \\
\hline House wife & 15 & 50 & 16 & 53.3 \\
\hline \multicolumn{5}{|l|}{ Parity } \\
\hline Primigravida & 16 & 53.3 & 15 & 50 \\
\hline Multigravida & 14 & 46.7 & 15 & 50 \\
\hline \multicolumn{5}{|l|}{ Gestational Age } \\
\hline 36-37 weeks & 10 & 33.3 & 0 & 0 \\
\hline 38-39 weeks & 17 & 56.7 & 28 & 93.3 \\
\hline 40 and above & 3 & 10 & 2 & 6.7 \\
\hline \multicolumn{5}{|l|}{ Type of delivery } \\
\hline Normal delivery with episiotomy & 11 & 36.7 & 14 & 46.7 \\
\hline Forceps/Vaccum delivery & 4 & 13.3 & 0 & 0 \\
\hline LSCS & 15 & 50 & 16 & 53.3 \\
\hline \multicolumn{5}{|c|}{ Breast problems in early pregnancy } \\
\hline Inverted nipple & 7 & 23.3 & 6 & 20 \\
\hline Flat nipple & 4 & 66.6 & 5 & 16.6 \\
\hline \multicolumn{5}{|l|}{ Any measures taken } \\
\hline Medical measures & 5 & 16.6 & 4 & 13.3 \\
\hline Self-measures & 6 & 20 & 7 & 23 \\
\hline \multicolumn{5}{|c|}{ Information regarding prevention of breast engorgement } \\
\hline Yes & 27 & 90 & 29 & 96.6 \\
\hline No & 3 & 10 & 1 & 3.3 \\
\hline \multicolumn{5}{|l|}{ Source of information } \\
\hline Parents & 13 & 46.6 & 6 & 20 \\
\hline Relatives & 3 & 10 & 10 & 33.3 \\
\hline Media & 5 & 16.7 & 6 & 23.3 \\
\hline Health workers & 6 & 20 & 7 & 20 \\
\hline Nil & 3 & 10 & 1 & 3.3 \\
\hline \multicolumn{5}{|l|}{ Examination done on breast } \\
\hline Yes & 3 & 10 & 11 & 36.6 \\
\hline No & 27 & 90 & 19 & 63.3 \\
\hline \multicolumn{5}{|l|}{ Milk production adequate } \\
\hline Yes & 10 & 33.3 & 17 & 56.6 \\
\hline No & 20 & 66.6 & 13 & 43.3 \\
\hline \multicolumn{5}{|c|}{ Discomfort experience during breast feeding } \\
\hline Yes & 6 & 20 & 7 & 23.3 \\
\hline No & 24 & 80 & 23 & 76.6 \\
\hline
\end{tabular}


Above $75 \%$ of mothers in both groups reported that no discomforts during previous pregnancy. Table 3 reveals that the practices of Positioning $\left(\chi^{2}=14.958\right)$ and Attachment $\left(\chi^{2}=14.880\right)$ aspects of BBAT shows significant difference $(\mathrm{p}=0.001)$ at $99.9 \%$ confidence interval whereas no significant difference in the sucking $\left(\chi^{2}=7.450\right)$ and swallowing $\left(\chi^{2}=12.437\right)$ aspects in which $\mathrm{p}=0.24$ and 0.002 respectively.

Table 2: Comparison of pre-test and post-test level of knowledge between experimental and control groups by using paired $\mathbf{t}$ test $\mathbf{n}=\mathbf{6 0}$.

\begin{tabular}{|llllll|}
\hline Group & Intervention & Mean & SD & t value & p value \\
\multirow{2}{*}{ Control } & Pre-test & 9.83 & 3.10 & \multirow{2}{*}{0.711} & \multirow{2}{*}{0.483} \\
\cline { 2 - 5 } Experimental & Post-test & 10.03 & 3.232 & \multirow{2}{*}{12.838} & $0.000^{* *}$ \\
\hline
\end{tabular}

$\mathrm{T}(29)=3.66 * *$ significant $\mathrm{p}<0.001$

Table 3: Comparison of practices of breastfeeding by bristol breastfeeding assessment tool (BBAT) by using chisquare test $n=60$.

\begin{tabular}{|c|c|c|c|c|c|c|c|}
\hline \multirow{3}{*}{ BBAT } & \multirow{3}{*}{ Category } & \multicolumn{4}{|c|}{ Groups } & \multirow{3}{*}{$\chi^{2}$ Value } & \multirow{3}{*}{ p Value } \\
\hline & & \multicolumn{2}{|c|}{ Control $(n=30)$} & \multicolumn{2}{|c|}{ Experimental $(n=30)$} & & \\
\hline & & $\mathbf{F}$ & $\%$ & $\mathbf{F}$ & $\%$ & & \\
\hline \multirow{3}{*}{ Positioning } & Good & 4 & 13.3 & 16 & 53.3 & \multirow{3}{*}{14.958} & \multirow{3}{*}{$0.001 * *$} \\
\hline & Moderate & 19 & 63.3 & 14 & 46.7 & & \\
\hline & Poor & 7 & 23.3 & 0 & 0 & & \\
\hline \multirow{3}{*}{ Attachment } & Good & 7 & 23.3 & 18 & 60 & \multirow{3}{*}{14.880} & \multirow{3}{*}{$0.001 * *$} \\
\hline & Moderate & 13 & 43.3 & 12 & 40 & & \\
\hline & Poor & 10 & 33.3 & 0 & 0 & & \\
\hline \multirow{3}{*}{ Sucking } & Good & 6 & 20 & 16 & 53.3 & \multirow{3}{*}{7.450} & \multirow{3}{*}{$0.024 \mathrm{~ns}$} \\
\hline & Moderate & 19 & 63.3 & 10 & 33.3 & & \\
\hline & Poor & 5 & 16.7 & 4 & 13.3 & & \\
\hline \multirow{3}{*}{ Swallowing } & Good & 4 & 13.3 & 17 & 56.7 & \multirow{3}{*}{12.437} & \multirow{3}{*}{$0.002 \mathrm{~ns}$} \\
\hline & Moderate & 19 & 63.3 & 9 & 30 & & \\
\hline & Poor & 7 & 23.3 & 4 & 13.3 & & \\
\hline
\end{tabular}

\section{DISCUSSION}

This study is focused to evaluate the effectiveness of prenatal teaching on prevention of breast engorgement in terms of knowledge, practice and incidence of breast engorgement. The researcher prepared a knowledge questionnaire to compare the mean pre-test and mean post-test knowledge on prevention of breast engorgement. The result of the study indicated that the mean pre-test knowledge level of control group is 9.833 of 3.10 and the post-test level is 10.0333 .232 whereas in the Experimental group, the mean pre-test level is 10.20 3.418 and the post-test level is 20.76 2.699. While comparing the ' $\mathrm{t}$ ' value of Control group is 0.711 and $\mathrm{p}$ value is 0.483 which is not statistically significant and the $\mathrm{t}$ value of Experimental group is 12.838 and $\mathrm{p}$ value is 0.000 , which is highly significant at 0.001 level.

The study results showed that the practice of breastfeeding by BBAT, which consists of four aspects named positioning, attachment, sucking and swallowing. Among the four aspects the Chi-square test revealed that positioning and attachment $\left(\chi^{2}=14.958\right)$ is significant at the level of 0.001 but other two aspects, sucking and swallowing $\left(\chi^{2}=7.450\right)$ and the $p$ value is 0.024 which is not significant.

Institute of Research in Medical Statistics (IRMS), Delhi undertook a study to assess nutritional intake as well as the knowledge attitude and practices about breast feeding in Bihar. About 8000 mothers (whose children up to 2 yrs of age) were interviewed by using probability sampling technique. Study revealed that about $29 \%$ of mothers started breast feeding within 24 hours. About two third of mothers discarded the colostrum on their own. One- third of the mothers discarded the colostrum on the advice of their elders. The main reason for this was the belief that colostrum is not good for the health of the newborn. The study reveals that adequate knowledge to the mothers regarding breast feeding is necessary to prevent the occurrence of breast engorgement. ${ }^{9}$

Ekambaram K conducted a study on knowledge, attitude and practice of breastfeeding among postnatal mothers. 
The data was collected from 100 postnatal mothers by trained interviewers using a structured proforma. Scoring of the responses to questions was done and the data was analysed using Statistical package for social sciences. The knowledge of the mothers was inadequate in areas of time of initiation of breastfeeding (62\%), colostrums feeding $(56 \%)$, duration of exclusive breastfeeding $(38 \%)$, knowledge on expressed breastmilk (51\%) and continuation of breastfeeding while baby is sick. Better scores correlated significantly with higher maternal age, better maternal education, higher socioeconomic status and having received antenatal care from tertiary care centres and private practitioners. The study results show that there is still a need for programmes, which support and encourage breastfeeding particularly at a primary care level, focusing more on younger, less well-educated women and those from lower socioeconomic classes. ${ }^{10}$

The present study results revealed that the incidence of breast engorgement in Control group is $63.3 \%$ of the mothers whereas in the Experimental group it is $13.3 \%$, which shows significant decrease in incidence of breast engorgement in Experimental group. The $\chi^{2}$ value is 15.864 and the $\mathrm{p}$ value is 0.000 which is significant. While comparing the results that of the literatures the findings were more or less consistent in nature, it may be due to influence of extraneous variables. Comparing the incidence of breast engorgement, $13.3 \%$ mothers only reported breast engorgement in experimental group whereas $63.3 \%$ in the Control group, which shows remarkable decrease in the incidence of breast engorgement in the former group.

\section{CONCLUSION}

Based on the findings, the study findings showed that there is a significant improvement in knowledge regarding prevention of breast engorgement and practices of breastfeeding especially in positioning and attachment of the babies compared to the findings of Control group. Incidence of breast engorgement is decreased in Experimental group than Control group. The prenatal teaching was effective and also the programme should be continued in order to improve the overall health and practices of breastfeeding among mothers thereby it reduces the incidence of breast engorgement.

Funding: No funding sources Conflict of interest: None declared
Ethical approval: The study was approved by the Thesis Review Committee of AIMS and Research Committee of Amrita College of Nursing, Amrita University, Kochi, India

\section{REFERENCES}

1. Lowdermilk, Perry, Maternity and Womens Health Care. $9^{\text {th }}$ ed. St. louis Missouri: Mosby publications; 2007:228-81.

2. Berens P, Brodribb W. The Academy of Breastfeeding Medicine. Breastfeeding medicine protocol committee. ABM clinical protocol \#20: Breastfeeding Medicine. 2016;11.

3. John L, Cordeiro MP, Manjima MG, Reshma Gopinath. Knowledge regarding breast problems among Antenatal Mothers in a selected hospital Mangalore with a view to develop an information booklet. Int J Recent Scient Res. 2015:6:6228-32.

4. Malini. Engorgement Incidence in India. Available from URL: http://www.incidence rates.com

5. Maheswari E. Knowledge, attitude and practice of breastfeeding among postnatal mothers. European $\mathbf{J}$ Scient Res. 2010;14(2):404-22.

6. Udayan S, Viswanath L, Varghese L. Awareness regarding Antenatal Investigations among Antenatal Mothers attending Selected Tertiary Hospital, Kochi, Kerala. J South Asian Federation Obstet Gynecol. 2014;6(3)129-32.

7. Annamma Jacob, A Comprehensive Text book of Midwives. $2^{\text {nd }}$ ed. Jaypee Publishers, New Delhi, 2008:436-7.

8. Bennet VR, Brown LK, Myles Text book For Midwives. $14^{\text {th }}$ ed. Churchill Livingstone, Newyork, 2000:762-3.

9. Yadav RJ, Singh P. Knowledge Attitude and Practices of Mothers about Breast Feeding in Bihar. Ind J Commu Medic. 2004;29(3):3.

10. Ekambaram M, Bhat BV and Mohammed Asif. PA. A study on Knowledge, attitude and practices of breastfeeding among postnatal mothers. Curr Pediatr Res. 2010;14(2):119-24.

Cite this article as: Padmasree SR, Varghese L, Krishnan AS. Effectiveness of prenatal teaching on prevention of breast engorgement. Int J Reprod Contracept Obstet Gynecol 2017;6:3927-31. 